\title{
ÍNDICE DE RECUPERAÇÃO DE OÓCITOS BOVINOS OBTIDOS DE OVÁRIOS ADQUIRIDOS EM ABATEDOURO COMO CONTRIBUIÇÃO PARA OS ESTUDOS DE FECUNDAÇÃO E PRODUÇÃO DE EMBRIÕES IN VITRO
}

AgostinHO, Juliana. Maria Avanci ${ }^{1}$

LÉGA, Elzylene ${ }^{2}$

\begin{abstract}
Recebido em: 2009-02-02
\end{abstract}
Aprovado em: 2009-04-29

Issue DOI: $10.3738 / 1982.2278 .164$

RESUMO: A produção in vitro de embriões é uma biotécnica utilizada, alternativamente, para acelerar a produção de animais geneticamente superiores além de permitir o aprofundamento dos conhecimentos relativos aos processos fisiológicos, bioquímicos e biotecnológicos da espécie animal de interesse. O desenvolvimento de técnicas in vitro para a produção de embriões de animais domésticos tem grande potencial tanto para pesquisa básica quanto para aplicações a campo e tem sido muito utilizadas e difundidas no Brasil e no mundo. O presente trabalho objetivou classificar oócitos bovinos obtidos de ovários adquiridos em abatedouro, determinando o índice de recuperação dessas estruturas e identificando os de maior viabilidade para o procedimento de fertilização in vitro. Através da aspiração folicular, foram obtidos oócitos posteriormente classificados em escala de 1 a 4, de acordo com a quantidade de camadas de células do complexo cumulus oophorus que envolvem o oócito. Observouse $15,22 \%$ de oócitos de qualidade $1 ; 25,88 \%$ de qualidade $2 ; 35,53 \%$ de qualidade 3 e $23,35 \%$ de qualidade 4 , determinando maiores índices de oócitos recuperados classificados na qualidade 2 e 3 , sendo estes fisiologicamente viáveis e capacitados para entrarem em um programa de fertilização in vitro.

Palavras-chave: Oócito. Bovino. Fecundação in vitro.

SUMMARY: The production of embryos in vitro is a biotechnology used, alternatively, to accelerate the production of genetically superior animals in addition to the deepening of knowledge concerning physiological processes, biochemical and biotechnological interest of the animal. The development of techniques in vitro to produce embryos of domestic animals has great potential both for basic research and for applications in the field and has been widely used and distributed in Brazil and abroad. This study aimed to classify bovine oocytes obtained from ovaries acquired in a slaughterhouse, determining the rate of recovery of these structures and identifying the most viable for the procedure for in vitro fertilization. Through follicular aspiration, oocytes were ranked in scale from 1 to 4 , according to the amount of layers of cells in the complex cumulus oophorus involving the oocyte. There was $15.22 \%$ of high-quality oocytes $1 ; 25.88 \%$ of quality $2 ; 35.53 \%$ from $23.35 \%$ quality 3 and quality 4 , setting higher rates of oocytes recovered classified as 2 and 3 , which are physiologically viable and able to enter into a program of in vitro fertilization.

Keywords: Oocyte. Bovine. In vitro production.

1 Graduanda do Curso de Medicina Veterinária - Faculdade Dr. Francisco Maeda, Ituverava, SP.

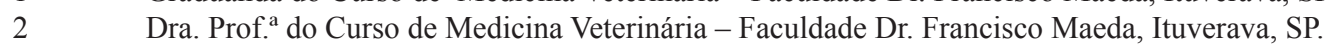




\section{INTRODUÇÃO}

O desenvolvimento de técnicas in vitro para a produção de embriões de animais domésticos tem grande potencial tanto para pesquisa básica quanto para aplicações a campo. O nascimento do primeiro bezerro resultante de fecundação in vitro de um oócito maturado in vivo foi em 1981. Posteriormente, as pesquisas se voltaram totalmente para a produção in vitro. A produção in vitro de embriões bovinos de animais de alto valor genético e zootécnico pode ser realizada também em animais postmorten, com a colheita das gônadas, ou através da técnica de punção folicular (ovum pick up; OPU) efetuada em doadoras vivas. A OPU, associada aos programas de produção in vitro, permite a redução do intervalo entre gerações de fêmeas prépúberes (KURTZ FILHO et al., 2003).

Segundo Gonçalves et al. (2002), a produção in vitro de embriões (PIV) envolve as etapas de colheita, maturação (MIV) e fecundação (FIV) de oócitos, bem como cultivo ou cocultivo (CIV) de zigotos e estruturas embrionárias. É uma biotécnica utilizada, alternativamente, para acelerar a produção de animais geneticamente superiores e através da aspiração in vivo de folículos guiada pela ultra-sonografia, especialmente em bovinos, impedir o descarte precoce de fêmeas geneticamente privilegiadas portadoras de alterações adquiridas, impedindo que a reprodução ocorra de forma natural ou até mesmo pela transferência de embriões. Além desses aspectos, a PIV também permite o aprofundamento dos conhecimentos relativos aos processos fisiológicos, bioquímicos e biotecnológicos da espécie de interesse do estudo, sem a necessidade de extrapolar resultados pertinentes a animais de laboratório.

Para a produção in vitro de embriões bovinos (PIV), os oócitos podem ser obtidos de ovários de abatedouros ou de animais vivos, neste último caso, pela ovariectomia, laparoscopia ou ainda através da aspiração folicular através de ultra-sonografia transvaginal (OPU) (LEIVAS et al., 2004).

O oócito, no interior do folículo, está envolto por células da granulosa, formando o complexo cumulus oopohorus (CCO). Apesar das células do cumulus não serem essenciais para a maturação dos oócitos, melhores resultados de maturação, fecundação e de desenvolvimento embrionário são alcançados na presença desse tipo celular, fato que evidencia a importância das células do cumulus na maturação do oócito in vitro (GONÇALVES et al., 2002).

Devido ao avanço da biotecnologia na reprodução animal, principalmente, na espécie bovina; levando em consideração as poucas limitações que a transferência de embriões proporciona, a produção in vitro de embriões se destaca como uma ferramenta indispensável na manutenção e evolução da genética de qualquer rebanho ou de espécies em extinção.

As biotécnicas da reprodução são utilizadas na pesquisa fundamental da compreensão da fisiologia reprodutiva e no controle da reprodução animal, empregando técnicas que visam tanto a contracepção como a multiplicação de animais. Os grandes impulsores das biotécnicas reprodutivas têm sido, sem dúvida, a necessidade do ser humano em conhecer o funcionamento da natureza para desenvolvimento de tecnologias, para o aumento da qualidade de vida, bem 
como a manipulação reprodutiva para o aumento da quantidade e qualidade alimentar para a sobrevivência humana. No primeiro caso, a respeito da fisiologia reprodutiva, o ser humano sempre buscou conhecer o funcionamento dos complexos mecanismos envolvidos na geração de um recém-nascido, incluindo a gênese e desenvolvimento dos gametas (espermatozóide e óvulo), o processo de fecundação e posterior desenvolvimento embrionário e fetal. No segundo caso, a respeito do controle da reprodução animal, o ser humano não se conforma com a enorme perda de gametas que ocorre nos processos naturais de reprodução. Para exemplificar, no touro, milhões de espermatozóides são ejaculados e apenas um pode fecundar o oócito. No caso da fêmea bovina, cerca de 300.000 oócitos estão presentes nos ovários ao nascimento. Entretanto, somente $300(0,1 \%)$ serão ovulados, sendo os demais $(99,9 \%)$ eliminados pelo processo de morte denominado atresia folicular (FIGUEIREDO et al., 2008).

As biotécnicas aplicadas à produção animal têm contribuído significativamente para a pesquisa, contribuindo para o esclarecimento das funções fisiológicas, a aumentar os índices de produtividade das diferentes espécies animais e a multiplicar animais em perigo de extinção. O domínio destas técnicas tem provocado uma verdadeira revolução científica. O controle do ciclo estral, associado à inseminação artificial em tempo fixo, a transferência de embriões, a produção in vitro de embriões, o diagnóstico precoce de gestação com o auxílio de ultra-som, a seleção assistida por marcadores moleculares, a manipulação de oócitos inclusos em folículos pré-antrais (MOIFOPA), a clonagem e a transgenia animal são algumas das biotécnicas que têm contribuído para derrubar dogmas científicos e extrapolar índices preestabelecidos de produção. Essa evolução tem progredido nas últimas décadas, conferindo aos países detentores destas tecnologias um progresso econômico significativo, tanto em relação às inovações tecnológicas, como às aplicações destas tecnologias para se obter sistemas de criação animal muito mais produtivos (GONÇALVES et al., 2002).

Dentre as vantagens, atuais e futuras, das biotécnicas reprodutivas destacam-se: ferramenta importante para compreensão da fisiologia reprodutiva feminina e masculina; multiplicação de animais geneticamente superiores; formação de bancos de geoplasma animal, reposição de espécies ameaçadas de extinção; controle populacional (métodos contraceptivos); aumento da produção de alimentos e outros produtos derivados dos animais (FIGUEIREDO et al., 2008).

Há mais de um século, foi observada, pela primeira vez, a fecundação de um óvulo de estrela do mar com a posterior formação da primeira célula do futuro embrião. Os invertebrados marinhos foram objetos das primeiras investigações porque, ao contrário dos mamíferos, a fecundação ocorre externamente ao sistema reprodutor da fêmea. Nos mamíferos, ainda no final da década de 20, surgiu o primeiro relato sobre a possibilidade de se cultivar embriões de coelhos desde os primeiros estádios de clivagem e na década seguinte foi registrada a primeira evidência do nascimento de láparos resultantes do cultivo in vitro de embriões. Todavia, somente na década de 50, é que foi registrado o nascimento do primeiro coelho gerado a partir da FIV. No que concerne aos animais de produção, apenas no final dos anos 70 é que surgiu 
o primeiro informe sobre a MIV e a FIV de oócitos bovinos e já no início de 80 constatava-se o nascimento do primeiro animal dessa espécie. A PIV em bovinos recebeu grande impulso ainda no final da década de 80 por ter sido verificado que poderia ser integralmente viabilizada sob condições artificiais. Nessa mesma década, mas sem grande repercussão, houve, também, relatos de nascimento de outras espécies ruminantes como ovinos e caprinos. Por todo potencial de aplicação que a PIV apresenta para as espécies humana e animal, como pela sua expressividade tanto para a ciência básica quanto para a aplicada, a técnica tem sido muito difundida e utilizada em diversos países, inclusive de forma destacada no Brasil, a partir da década de 90 (GONÇALVES et al., 2002).

Dentro desse contexto, o entendimento da oogênese se torna relevante. A formação dos folículos ovarianos e, consequentemente dos oócitos, notadamente nos ruminantes, tem início no período pré-natal. O processo de liberação dos oócitos pelos folículos ovarianos é precedido pelos eventos da foliculogênese e oogenêse (FIGUEIREDO et al., 2002).

A oogênese é o conjunto de processos envolvidos no desenvolvimento e diferenciação das células germinativas primordiais até a formação do oócito haplóide fecundado (RÜSSE, 1983). Antes da inserção da célula oocitária no folículo ovariano, ocorrem nela evolução de dois tipos celulares sucessivos, as células germinativas primordiais (CGP) e as oogônias. As primeiras têm origem extragonadal com formação durante o período embrionário, onde após a fecundação do oócito pelo espermatozóide, ocorre à formação e evolução do zigoto até o estádio de blastocisto, que é constituído pelo trofoblasto e embrioblasto. A partir do embrioblasto serão formados o ectoderma, o mesoderma e o endoderma. Do endoderma, tem origem o saco vitelínico e deste, as células germinativas primordiais, as quais, caracterizadas pela mobilidade e serem altamente invasivas (HIRSFIELD, 1991). Nos bovinos e ovinos, ainda durante a vida fetal, as células germinativas primordiais migram para o mesênquima da crista genital, ocupam a gônada indiferenciada (WASSARMAN, 1994), perdem a capacidade de mobilidade e multiplicam-se por mitose, podendo na espécie bovina, atingir dois milhões de células por indivíduo (ERICKSON, 1966). Em seguida, há um marcante processo de crescimento celular e redistribuição de organelas citoplasmáticas, as células germinativas primordiais multiplicamse de forma ativa e diferenciam-se em oogônias. Nestas, haverá sucessivas mitoses, em seguida, ocorrerá o estádio de prófase I e, são denominadas de oócitos primários. Nos núcleos dos oócitos que se encontram na fase de meiose I, ocorrerão, sucessivamente, os estádios de leptóteno, zigóteno, paquíteno e diplóteno. Neste último estádio, também denominado de vesícula germinativa, ocorrerá à primeira parada de meiose que permanecerá pelo menos até que o animal alcance a puberdade. No período em que o núcleo oocitário permanecer na fase de prófase I, o oócito, conjuntamente com as células somáticas, as quais locadas no compartimento folicular, efetuam intensa fase de crescimento, caracterizada por um incremento na atividade transcripcional (síntese de RNA), acúmulo de lipídeos e absorção ativa e/ou passiva de diferentes nutrientes. Com o início da puberdade, algumas horas antes da ovulação, ocorrerão liberações pré-ovulatórias de LH, em decorrência, o estádio de meiose é retomado e o núcleo oocitário 
inicia a diacinese. Em seguida, ocorre condensação da cromatina, dando início ao processo de rompimento da vesícula germinativa. Ocorre, então, o desaparecimento do nucléolo compacto e do envelope nuclear e sucessivamente as fases de metáfase I, anáfase I e telófase I, com a expulsão do primeiro corpúsculo polar e formação do oócito secundário, que é caracterizado por seu núcleo se encontrar na segunda divisão meiótica (TSAFRIRI; KRAICER, 1972; DEKEL et al., 1988; BETTERIDGE et al., 1989; HYTTEL et al., 1989; SUN; MOOR, 1991; SUM et al., 2001; SILVA et al., 2002).

Na segunda divisão meiótica, a fase de prófase II, caracterizada por ocorrer de forma rápida e, às vezes, inexistente avança até a fase de metáfase II, culminando com a segunda parada da meiose, estando o oócito nuclear e citoplasmaticamente apto para reiniciar o processo. Para a retomada da meiose, o oócito deverá ser fecundado pelo espermatozóide, então, no núcleo oocitário ocorrerá, sucessivamente, os estádios de anáfase II e telófase II, expulsão do segundo corpúsculo polar e formação do oócito haplóide fecundado, determinando o encerramento do processo da oogênese (MILOVANOV; SIRARD, 1994; RUMPF et al., 1995; GONÇALVES et al., 2002).

Os oócitos possuem diferentes aspectos morfológicos que determinam sua viabilidade. Várias classificações morfológicas têm sido adotadas para selecionar oócitos bovinos na tentativa de identificar os de maior viabilidade.

De acordo com Leibfried; First (1979), os oócitos podem ser classificados em escala de 1 a 4, considerando-se as características do cumulus e do citoplasma do oócito (ooplasma), onde:

a) Qualidade 1: cumulus compacto presente, contendo mais de três camadas de células, ooplasma com granulações finas e homogêneas, preenchendo o interior da zona pelúcida e de coloração marrom;

b) Qualidade 2: cumulus compacto parcialmente presente em volta do oócito ou rodeando completamente o oócito, com menos de três camadas celulares, ooplasma com granulações distribuídas heterogeneamente, podendo estar mais concentradas no centro e mais claras na periferia ou condensadas em um só local aparentando uma mancha escura, preenchendo o espaço do interior da zona pelúcida;

c) Qualidade 3: cumulus presente, mas expandido, com ooplasma contraído, com espaço entre a membrana celular e a zona pelúcida, preenchendo irregularmente o espaço perivitelino, degenerado, vacuolizado ou fragmentado;

d) Qualidade 4: oócito desnudo ou sem cumulus.

Outras classificações quanto à qualidade dos oócitos são previstas, podendo citar também a classificação segundo Loos et al. (1991) (TETZNER, 2007), onde:

a) Grau I: revestimento com multicamadas de cumulus compacto, ooplasma homogêneo e complexo cumulus-oócito claro e transparente;

b) Grau II: revestimento com 3 a 5 camadas de cumulus compacto, ooplasma homogêneo ou com regiões escuras na periferia;

c) Grau III: pouco revestimento de células do cumulus (1 a 3 camadas) e ooplasma irregular 
com picnose;

d) Grau IV ou atrésico: cumulus expandido com células escuras e em grumos, e complexo cumulus-oocitário escuro e irregular;

e) Desnudo: sem camadas do cumulus e com ooplasma uniforme ou com granulações.

O oócito pode ter o seu potencial de maturação, fecundação e capacidade de desenvolvimento embrionário estimado pela aparência do CCO. Morfologicamente, os oócitos com maior potencial de viabilidade devem apresentar ooplasma homogêneo com granulações finas, de coloração marrom e completamente envolvidos por várias camadas de células do cumulus dispostas de forma compacta (GONÇALVES et al., 2002).

A capacidade de oócitos mamíferos em maturar in vitro está correlacionada com a atividade ovariana, o crescimento folicular e a presença ou ausência de células do cumulus, formando $\mathrm{CCO}$, sendo esse último, necessário para o transporte de energia e a promoção da maturação do oócito bovino. A presença de células do cumulus circundando os oócitos parece ser mais importante para a maturação in vitro que até mesmo a atividade ovariana ou o tamanho folicular (SATO et al., 1977; FUKUI; SAKUMA, 1980).

As células do cumulus oophorus apresentam-se em policamadas compactas e, por ocasião da maturação, sob o estímulo dos hormônios LH e FSH entram em processo de expansão, interrompendo as comunicações com o oócito (HYTTEL, 1987, 1988; SZÖLLÖSI, 1991). Essas células, assim como às da granulosa, são essenciais na nutrição, crescimento, divisão meiótica, maturação citoplasmática e na fecundação do oócito, (EPPIG, 1980; FUKUI; SAKUMA, 1980). Nas células somáticas que envolvem o oócito, durante as maturações citoplasmática e nuclear, ocorrem modificações morfológicas específicas. As células do cumulus iniciam um arranjo na matriz extracelular, rica em ácido hialurônico, e tal fenômeno é denominado de expansão ou mucificação das células do cumulus (EPPIG et al., 1982; BUCCIONE et al., 1990). In vitro, a expansão das células do cumulus é visível a partir das 12 horas de cultivo (SUTOVSKY et al., 1993). A presença considerável de glicosaminoglicanos nas células do cumulus impede a ação do estresse oxidativo dos radicais livres sobre os oócitos, evitando a redução na taxa de clivagem (LUVONI et al., 1996), e o choque térmico que bloqueia a síntese de proteínas (EDWARDS; HANSEN, 1997).

A remoção das células do cumulus de oócitos oriundos de pequenos folículos antrais afeta sua habilidade para atingir a maturação nuclear e citoplasmática (SUM et al., 2001). Nesse contexto, em procedimentos de obtenção de oócitos em abatedouros para produção in vitro de embriões, Alves et al (2001), Coelho et al (2002), Kurtz Filho et al. (2003), Figueiró et al (2004) e Leivas et al (2004), utilizaram, em seus experimentos, substâncias antibióticas para prevenir a degradação das células do cumulus oophorus, conservando a qualidade dos oócitos.

Desta forma, o presente trabalho teve como objetivo classificar oócitos bovinos obtidos de ovários adquiridos em abatedouro, visando a determinar o índice de recuperação dessas estruturas, identificando e classificando os de maior viabilidade como treinamento básico para estudos e procedimentos relacionados à fecundação e produção de embriões in vitro. 


\section{MATERIAL E MÉTODOS}

Este trabalho foi realizado no Laboratório de Reprodução Animal do Hospital Veterinário da Faculdade Doutor Francisco Maeda - FAFRAM - Ituverava SP, durante o período de setembro a outubro de 2008.

Para a realização do experimento foram utilizados ovários de fêmeas bovinas provenientes do abatedouro localizado no município de Guará SP, região de Ituverava, SP.

Os ovários bovinos foram transportados para o laboratório em garrafa térmica contendo solução salina a $0,9 \%$ de $\mathrm{NaCl}$ na temperatura de $37^{\circ} \mathrm{C}$, em um período máximo de uma hora.

Em três repetições, utilizou-se um total de 50 ovários, nos quais foram realizadas aspirações foliculares com auxílio de seringas de $20 \mathrm{~mL}$ com extremidade de agulha $18 \mathrm{G}$ (Figura 1). Os ovários, após serem lavados em frascos contendo solução salina, foram mantidos em banho-maria a $37^{\circ} \mathrm{C}$ até a aspiração. Estes foram submetidos à secagem com gaze estéril, antes da punção folicular. Terminada a aspiração, o líquido folicular aspirado foi transferido a tubos de ensaio mantidos em banho-maria a $37^{\circ} \mathrm{C}$ e decantado para separação dos oócitos (Figura 2).

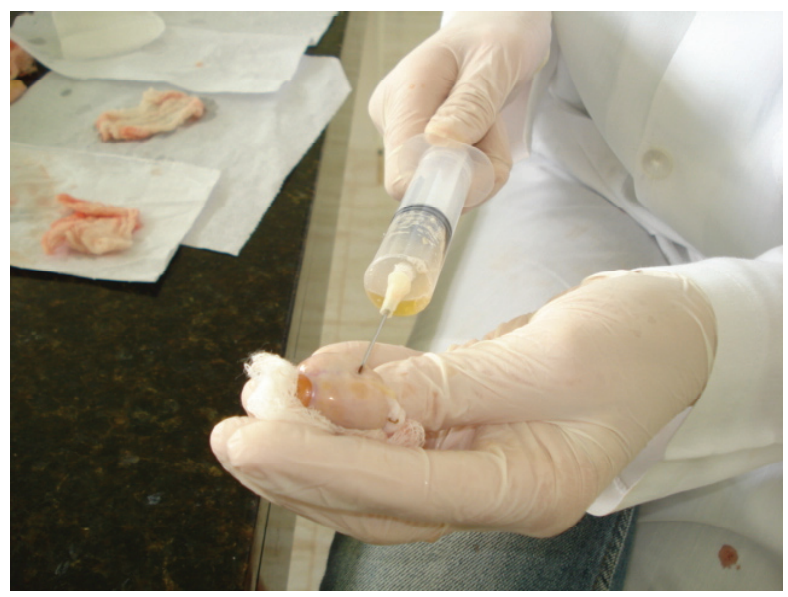

FIGURA 1: Imagem fotográfica do procedimento de aspiração folicular para obtenção dos oócitos. Laboratório de Reprodução Animal. Faculdade Dr. Francisco Maeda - FAFRAM - Ituverava-SP, 2008.

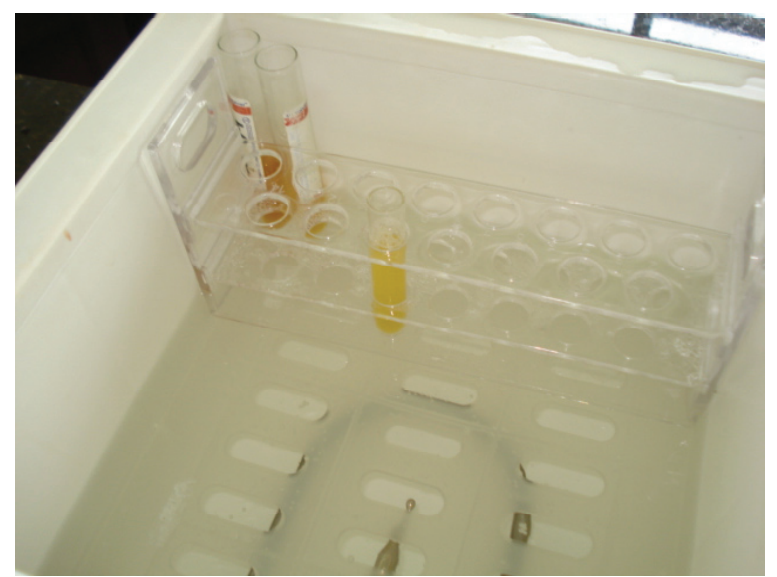

FIGURA 2: Imagem fotográfica dos tubos de ensaio contendo líquido folicular (setas), mantidos em banhomaria. Laboratório de Reprodução Animal. Faculdade Dr. Francisco Maeda - FAFRAM - Ituverava-SP, 2008. 
Após desprezar-se o sobrenadante, o sedimento foi depositado em placa de petri marcada para rastreamento e isolamento dos oócitos e CCOs, utilizando-se lupa estereomicroscópica com aumento de 4,5X. Posteriormente, os oócitos recuperados foram classificados de acordo com a proposição de Leibfried; First (1979) em escala de 1 a 4.

\section{RESULTADOS E DISCUSSÃO}

No primeiro dia de colheita, foram adquiridos 16 ovários, identificando-se 41 oócitos; no segundo dia, obtiveram-se 20 ovários, sendo identificados 92 oócitos; no terceiro dia o número de ovários colhidos foi 14, identificando-se 64 oócitos. Totalizando-se, nas três repetições de colheita, 50 ovários, fornecendo 197 oócitos identificados e classificados (Tabela 1).

Dos oócitos obtidos, identificando-se 30 de qualidade 1, apresentando nitidamente mais de três camadas de células do cumulus (Figura 3a); 51 de qualidade 2, apresentando cumulus com menos de três camadas celulares (Figura 3b); 70 de qualidade 3, apresentando cumulus expandido (Figura 3c); e 46 de qualidade 4, apresentando-se desnudos (Figura 3d). Os resultados obtidos podem ser sumarizados na tabela 1.

A classificação de acordo com Leibfried; First (1979) foi adotada no presente trabalho por ser a mais padronizada para este fim.

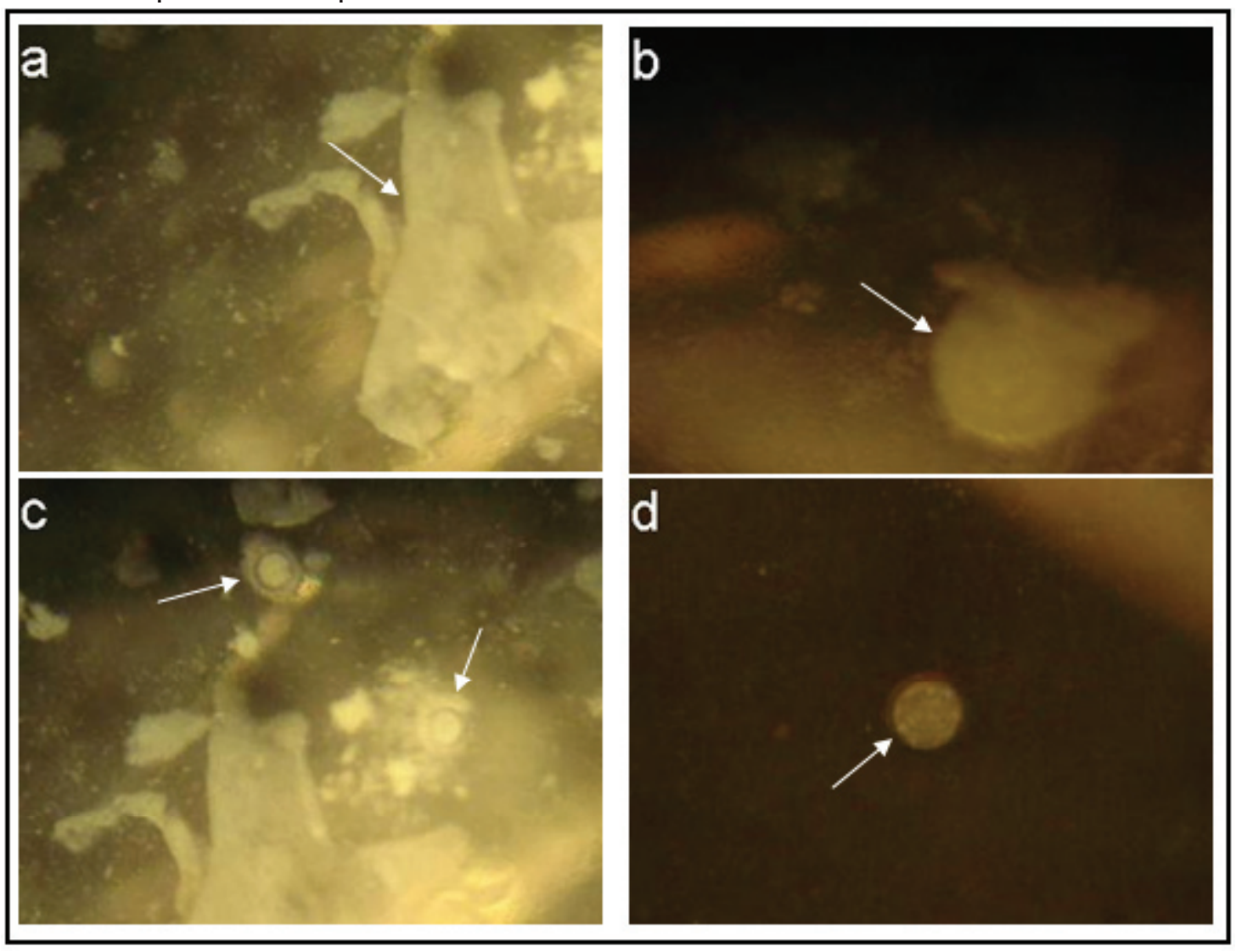

FIGURA 3: Imagem fotográfica do aspecto morfológico dos CCOs e oócitos bovinos identificados sob lupa estereomicroscópica. (a) Qualidade 1; (b) Qualidade 2; (c) Qualidade 3; (d) Qualidade 4. Laboratório de Fitopatologia. Faculdade Dr. Francisco Maeda - FAFRAM - Ituverava-SP, 2008. 
TABELA 1 - Número de oócitos por colheita e distribuição de sua classificação. Ituverava-SP, 2008.

\begin{tabular}{ccccccc}
\hline \multirow{2}{*}{$\mathrm{N}^{\circ}$ da } & $\mathrm{N}^{\circ}$ de & $\mathrm{N}^{\circ} \mathrm{de}$ & \multicolumn{4}{c}{ Qualidade } \\
\cline { 4 - 7 } colheita & ovários & oócitos & $1 \mathrm{n} *(\%)$ & $2 \mathrm{n}(\%)$ & $3 \mathrm{n}(\%)$ & $4 \mathrm{n}(\%)$ \\
\hline $1^{\text {a colheita }}$ & 16 & 41 & $10(24,39)$ & $11(26,82)$ & $16(39,00)$ & $4(9,75)$ \\
$2^{\text {a }}$ colheita & 20 & 92 & $10(10,86)$ & $25(27,17)$ & $34(36,95)$ & $23(25,00)$ \\
$3^{\mathrm{a}}$ colheita & 14 & 64 & $10(15,62)$ & $15(23,43)$ & $20(31,25)$ & $19(29,68)$ \\
Média & & 65,67 & $10(16,96)$ & $17(25,80)$ & $23,33(35,73)$ & $15,33(21,47)$ \\
Desvio padrão & & 25,54 & 0 & 7,21 & 9,45 & 10,02 \\
\hline Total & 50 & 197 & $30(15,22)$ & $51(25,88)$ & $70(35,53)$ & $46(23,35)$ \\
\hline
\end{tabular}

*n: número de oócitos obtidos em cada qualidade.

Os ovários foram obtidos em animais da espécie bovina de forma aleatória, sem preocupação com a idade da fêmea, visto que os oócitos estão presentes nas fêmeas desde o nascimento (FIGUEIREDO et al., 2008).

Obtiveram-se maiores índices de oócitos recuperados classificados nas qualidades de $2(25,88 \%)$ e $3(35,53 \%)$, ou seja, oócitos com cumulus compactos parcialmente presentes com menos de três camadas de células e oócitos com cumulus presentes, mas expandidos, respectivamente.

Leivas et al. (2004) descreveram em seu experimento que, para a PIV, os oócitos obtidos a partir de ovários provenientes de frigorífico, foram transportados até o laboratório a $30^{\circ} \mathrm{C}$, em solução de $\mathrm{NaCl}$ a $0,9 \%$, acrescida de $50 \mathrm{UI} / \mathrm{mL}$ de penicilina G-potássica e $100 \mathrm{mg} / \mathrm{mL}$ de estreptomicina. Os folículos foram aspirados com auxílio de uma bomba de vácuo. No entanto, Kurtz Filho et al. (2003) e Figueiró et al. (2004), em seus experimentos, coletaram os ovários em frigorífico e os transportaram até o laboratório em solução de $0,9 \%$ de $\mathrm{NaCl}$ acrescida de $50 \mathrm{UI} / \mathrm{ml}$ de penicilina G-potássica, à temperatura ambiente $\left(22\right.$ a $\left.25^{\circ} \mathrm{C}\right)$. Os folículos, também, foram puncionados com auxílio de uma bomba de vácuo.

Coelho et al. (2002) obtiveram ovários em abatedouros, sendo estes transportados para o laboratório a temperatura ambiente $\left(25-30^{\circ} \mathrm{C}\right)$, e dentro de frascos de vidros contendo solução salina a $0,9 \%$, acrescidos de sulfato de gentamicina $(50 \mu \mathrm{g} / \mathrm{mL})$ e fungizon $(2,5 \mu \mathrm{g} / \mathrm{mL})$. Alves et al. (2001), em seu experimento, descrevem que os ovários, também, obtidos em abatedouro, eram transportados ao laboratório em garrafa térmica contendo solução fisiológica acrescida de $30 \mu \mathrm{g} / \mathrm{mL}$ de sulfato de gentamicina em temperatura variando de 30 a $35^{\circ} \mathrm{C}$. Neste, os folículos foram aspirados com auxílio de seringa de $5 \mathrm{~mL}$ e agulha $18 \mathrm{G}$.

Substâncias como Penicilina G-Potássica, estreptomicina, sulfato de gentaminicina e fungizon são utilizadas junto à solução salina no transporte dos ovários nos experimentos citados, porque nestes, os oócitos puncionados foram colocados para maturar e posteriormente realizada a fecundação in vitro. No presente trabalho, estas substâncias não foram utilizadas devido ao fato de que os oócitos não foram selecionados para maturação, sendo apenas submetidos à classificação. Todavia, Tetzner (2007) obteve bons resultados na realização da 
FIV não adicionando substâncias antibióticas à solução salina utilizada para o transporte dos ovários do frigorífico ao laboratório.

Nos trabalhos retro-mencionados, foi citada a produção de embriões, o que sugere a utilização de oócitos nas qualidades 1 e 2 , porém os autores não relataram a porcentagem de ocorrência de cada qualidade.

Apesar de os maiores índices de oócitos recuperados tenham sido os de qualidade 2 e 3 , oócitos de qualidade 1, fisiologicamente viáveis e capacitados para entrarem em um programa de fecundação in vitro (FIGUEIREDO et al., 2002), também puderam ser encontrados utilizandose apenas solução salina de $\mathrm{NaCl}$ a $37^{\circ} \mathrm{C}$ para o procedimento de transporte dos ovários do abatedouro para o laboratório.

O baixo índice de oócitos na qualidade 1 encontrado (15,22\%) pode ter ocorrido devido à ausência da adição de antibióticos nos ovários durante o transporte destes, já que estas substâncias preveniriam a contaminação por bactérias destas estruturas, quando expostas ao ambiente, conservando a qualidade dos oócitos. Este fato sugere a hipótese de se classificar oócitos em outra oportunidade, utilizando-se antibióticos.

\section{CONCLUSÃO}

a) Foi possível obter oócitos de ovários bovinos adquiridos em abatedouro;

b) Foi possível classificar os oócitos obtidos nas quatro qualidades propostas na literatura;

c) O método de colheita sem antibiótico permitiu encontrar oócitos de qualidades 1 e 2;

d) Pelo método utilizado, foi possível obter oócitos de qualidades 1 e 2 que podem ser levados para procedimentos de maturação e fecundação in vitro.

\section{REFERÊNCIAS}

ALVES, J. R. et al. Altas concentrações de FSH-p na maturação in vitro de oócitos Bos indicus. Revista Ciência Rural, Santa Maria-RS, v.31, n.4, p.645-649, 2001.

BETTERIDGE, K. J.et al. Potencial genetic improvement of cattle by fertilization of fetal oocytes in vitro. Journal of Reproduction and Fertility, v.38, p.87-98, 1989.

BUCCIONE, R.; SCHROEDER, A.; EPPIG, J. Interactions between somatics cells and germ cells throughout mammalian oogenesis. Biology of Reproduction, v.43, p.543-547, 1990.

COELHO, L. A.et al. Produção in vitro de embriões bovinos: Utilização de diferentes fontes de gonadotrofinas na maturação dos oócitos. R. Bras. Zootec., n.3, p.1117-1121, 2002. 
DEKEL, N.; GALIANI, D.; BEERS, W. Induction of maturation in follicle-enclosed oocytes: the response to gonadotropins at different stages of follicular development. Biology of Reproduction, v.38, p.517-521, 1988.

EDWARDS, J. L.; HANSEN, P. J. Differential responses of bovine oocytes and preimplantation to heat shock. Molecular Reproduction and Development, v.46, p.138-145, 1997.

EPPIG, J. J. Regulation of cumulus oophorus expansion by gonadotropins in vivo and in vitro. Biology of Reproduction, v.23, p.545-552, 1980.

EPPIG, J. J.et al. Differential action of sulfated glycosaminoglycans on follicle stimulating hormone-induced functions of cumuli oophori isolated from mice. Biology of Reproduction, v.27, p.399-406, 1982.

ERICKSON, B. H. Development and senescence of the postnatal bovine ovary. 1966. In: GONÇALVES, P. B. D.; FIGUEIREDO, J. R.; FREITAS, J. V. F. (Eds.) Biotécnicas aplicadas à reprodução. São Paulo: Varela, 2002. Cap.11, p.227-260.

FIGUEIREDO, J. R.; GONÇALVES, P. B. D.; VISINTIN, J. A. Princípios básicos, importância e desafios das biotécnicas aplicadas à reprodução animal. Revista CFMV - Brasília/DF, ano XIV, n.44, p. 20-27, 2008.

FIGUEIREDO, J.R.; RODRIGUES, A.P.R.; AMORIM, C.A. Manipulação de oócitos inclusos em folículos ovarianos pré-antrais-MOIFOPA. In: GONÇALVES, P. B. D.; FIGUEIREDO, J. R.; FREITAS, J. V. F. (Eds.) Biotécnicas aplicadas à Reprodução Animal. São Paulo: Varela, 2002. Cap.11, p.227-260.

FIGUEIRÓ, G. M.et al. Produção in vitro de embriões bovinos com soro de égua ou de vaca em estro com ou sem a adição de LH/FSH. Ciência Rural, Santa Maria-RS, v.34, n.2, p.479484, mar-abr, 2004.

FUKUI, Y.; SAKUMA, Y. Maturation of bovine oocytes cultured in vitro: relation to ovarian activity, follicular size and the presence or absence of cumulus cell. Biology of Reproduction, Champaign, v.22, p.669-673, 1980.

GONÇALVES, B. D.; FIGUEIREDO, J. R.; FREITAS, V. J. F. Biotécnicas aplicadas à Reprodução Animal. São Paulo: Varela, 2002. p. 195-226.

Nucleus Animalium, v.1, n.1, maio 2009 
HIRSHFIELD, A.N. Development of follicles in the mammalian ovarian. International review of cytology, v.124, p.43-101, 1991. In: GONÇALVES, P. B. D.; FIGUEIREDO, J. R.; FREITAS, J. V. F. (Eds.) Biotécnicas aplicadas à Reprodução Animal. São Paulo: Varela, 2002. Cap.11, p.227-260.

HYTTEL, P. Bovine cumulus-oocyte desconnection in vitro. Anatomy and Embryology, v.176, p.41-44, 1987.

HYTTEL, P. Oocyte maturation and fertilization in cattle - ultrastructural aspects. Copenhagen; A/S Carl F. Moertensen, 1988.

HYTTEL, P.; GREVE, T.; CALLESEN, H. Ultrastructural aspects of oocyte maturation and fertilization in cattle. Journal of Reproduction and Fertility, v.38, p.35-47, 1989.

KURTZ FILHO, M.et al. F. Produção in vitro de embriões bovinos em tubos sem controle da atmosfera gasosa. Braz. J. Vet. Res. Anim. Sci., 2003, v.40, n.3, p.209-216. ISSN 1413-9596.

LEIBFRIED, L.; FIRST, N. L. Characterization of bovine follicular oocytes and their ability to mature in vitro. Journal of Animal Science, v. 48, p. 76-86, 1979.

LEIVAS, F. G.et al. Transporte de oócitos bovinos em meio de maturação sem controle de atmosfera gasosa. Cienc. Rural, jan./fev. 2004, v.34, n.1, p.219-224. ISSN 0103-8478.

LUVONI, G. C.; KESKINTEPE, L.; BRACKETT, B. G. Improvement in bovine embryo production in vitro by glutathione-containing media. Molecular reproduction and development, v.43, p.437-443, 1996.

MILOVANOV, C.; SIRARD. M. A. Manipulation of chromosome condensation by protein synthesis inhibitors and cyclic maturation of bovine oocytes. Theriogenology, v.41, n.4, p.819827, 1994.

RUMPF, R.et al. Fecundação in vitro na espécie bovina: a experiência do CENARGEN. Revista Brasileira de Reprodução Animal, Belo Horizonte-MG, v.19, n.3-4, p.219-232, 1995.

RÜSSE, I. Oogenesis in cattle and sheep. Biblie Anatomic, v. 24, p.77-92, 1983. In: GONÇALVES, P. B. D.; FIGUEIREDO, J. R.; FREITAS, J. V. F. (Eds.) Biotécnicas aplicadas à Reprodução Animal. São Paulo: Varela, 2002. Cap.11, p.227-260. 
SATO, E.; IRITANI, A.; NISHIKAWA, Y. Factors involving in vitro maturation of pig and cattle follicular oocytes cultured in vitro. Japanese Journal of Animal Reproduction, Tokyo, v.23, p.12-18, 1977.

SILVA, J. R. V.et al. Características morfológicas e controle do crescimento folicular durante a foliculogênese em ruminantes domésticos. Ciência Animal, Fortaleza-CE, v.12, n.2, p.105$117,2002$.

SUM, Q. Y.et al. Cytoplasmic changes in relation to nuclear maturation and early embryo developmental potential of porcine oocytes: effects of gonadotropins, cumulus cells, follicular size, and protein synthesis inhibition. Molecular Reproduction and Development, v.59, n.2, p.192-198, 2001.

SUN, F. Z.; MOOR, R. M. Nuclear-citoplasmic interations during ovine oocyte maturation. Development, v.111, p.171-180, 1991.

SUTOVSKY, P. Et al. Dynamic changes of gap junctions and cytoskeleton during in vitro of culture of cattle oocyte cumulus complexes. Biology of Reproduction, v.49, p.1277-1287, 1993.

SZÖLLÖSI, D. Maturation de l'ovocyte. In THIBAULT, C. ; LEVASSEUR, M. C.: La reproduction chez les mammifères et l'homme. Paris, INRA/Ellipses, 1991.

TSAFRIRI, A.; KRAICER, P. The time of ovum maturation in the rat. Journal of Reproduction and Fertility, v.29, p.387-393, 1972.

TETZNER, T. A. D. Efeitos da substituição do soro fetal bovino (SFB) e da albumina sérica (BSA) pela ovalbumina (OVA) na produção in vitro de embriões bovinos. 2007. 92f.. Dissertação (mestrado). Faculdade de Ciências Agrárias e Veterinárias. Universidade Estadual Paulista.

WASSARMAN, P. M.; ALBERTINI, D. F. The mammalian ovum. In: KNOBIL, E.; NEIL, J. D. (eds). The Physiology of Reproduction, 2. ed. New York: Raven Press, 1994.

Nucleus Animalium, v.1, n.1, maio 2009 